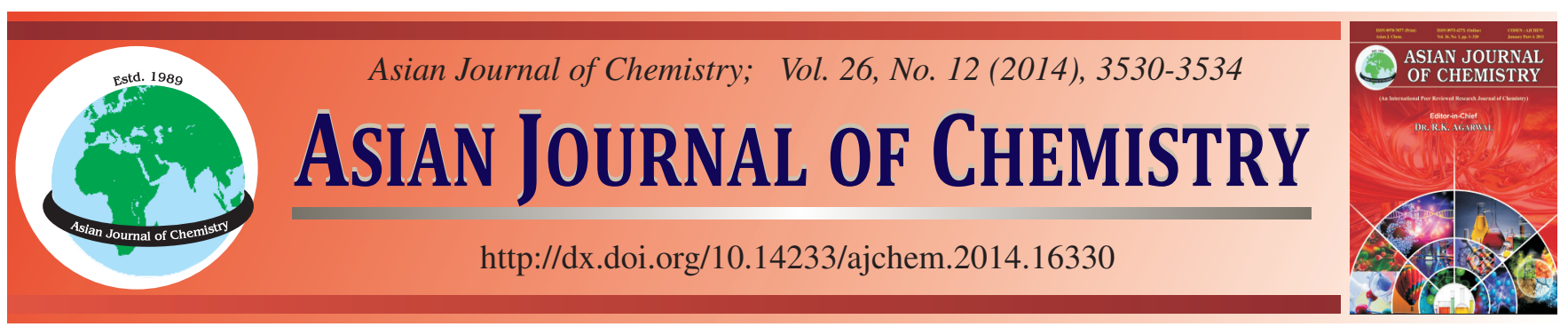

\title{
Sensitive Liquid Chromatographic Assay for Simultaneous Determination of Olmesartan and Its Prodrug Olmesartan Medoxomil in Rabbit Plasma
}

\author{
T. Sharma ${ }^{1, *}$, S.K. Moitra ${ }^{1}$, D. GowrisanKAR ${ }^{2}$ and S.C. $\mathrm{Si}^{1}$
}

${ }^{1}$ School of Pharmaceutical Sciences, Siksha 'O' Anusandhan University, Bhubaneswar-751 003, India

${ }^{2}$ Department of Pharmaceutical Sciences, College of Pharmacyndhra University, Vishakhapatnam-530 003, India

*Corresponding author: E-mail: tripti_neema@yahoo.co.in

Received: 11 September 2013;

Accepted: 28 November 2013;

Published online: 5 June 2014;

AJC-15289

\begin{abstract}
A rapid, sensitive, precise and accurate reverse phase liquid chromatographic (RP-HPLC) method was developed and validated for olmesartan and its prodrug olmesartan medoxomil in rabbit plasma. The method was developed on symmetry C18 column $(4.6 \mathrm{~mm} \times 150$ $\mathrm{mm}, 5 \mu \mathrm{m})$ using a mobile phase of acetonitrile: $0.1 \%$ aqueous triethylamine adjusted to $\mathrm{pH} 6$ with orthophosphoric acid $(90: 10 \mathrm{v} / \mathrm{v})$. The peaks were eluted at $254 \mathrm{~nm}$ wavelength and no interferences found from plasma. The total run time was 10 min with a flow rate of $1 \mathrm{~mL} / \mathrm{min}$. Calibration plots were linear over the range of $2-100 \mathrm{ng} / \mathrm{mL}$ for olmesartan medoxomil and $0.5-20 \mathrm{ng} / \mathrm{mL}$ for olmesartan. Retention time of olmesartan medoxomil, olmesartan and internal standard (irbesartan) were 3.23, 4.85 and 6.90 min, respectively. The method has been successfully applied to pharmacokinetic studies of olmesartan medoxomil and olmesartan in rabbits. The results demonstrated that olmesartan medoxomil was rapidly and totally converted to its parent drug, olmesartan following oral administration. Olmesartan medoxomil is a prodrug of olmesartan.
\end{abstract}

Keywords: Olmesartan medoxomil, Olmesartan, Prodrug, Pharmacokinetic, Plasma.

\section{INTRODUCTION}

Ester prodrugs are hydrolyzed to their pharmacologically active metabolites after absorption. Esterases present in the small intestine, plasma and liver are involved in this process. In most cases, intestinal esterases serve as the major enzymes in activation of prodrugs during the first pass through the gut after absorption. However, prodrugs that are relatively resistant to hydrolysis by intestinal esterases enter the blood circulation and are activated by serum (plasma) and liver esterases. The major hydrolyzing enzymes in serum are cholinesterase, aryl esterase, carboxyl esterase and albumin. The relative importance of each serum esterase in prodrug activation varies among animal species and prodrugs ${ }^{1}$.

Olmesartan medoxomil (5-methyl-2-oxo-1,3-dioxolen-4yl) methoxy-4-(1-hydroxyl-1-methylethyl)-2-propyl-1-\{4-[2(tetrazol-5-yl)-phenyl]phenyl \}methylimi-dazol-5-carboxylate] is a novel non peptide angiotensin II receptor antagonist that acts as an antihypertensive prodrug . After oral administration, olmesartan medoxomil is rapidly de-esterified in vivo via the aryl esterase enzyme, producing an active acid metabolite, olmesartan (Fig. 1) $)^{1}$. This enzyme is found in both the intestine and plasma. The conversion of olmesartan medoxomil to the active agent olmesartan occurs rapidly via the breakdown of the medoxomil ester moiety ${ }^{2-5}$.
Hydrolysis of olmesartan medoxomil in serum has been observed in several species and comparison among five species has shown that hydrolytic activity is highest in rabbits, followed by dogs, mice, rats and humans ${ }^{6}$. The medoxomil ester of olmesartan was developed in preference to the active compound olmesartan, because the oral bioavailability of the latter is low $(4.5 \% \text { ) and is increased (to } 28.6 \%)^{5}$ by esterification with the medoxomil moiety. However, only a fraction (26\%) of the administered dose is available systemically and, of this, up to half is excreted in the urine and the remainder in the faeces with unabsorbed drug ${ }^{2,5}$.

A literature survey revealed that several analytical methods were reported for the determination of olmesartan medoxomil in pharmaceutical dosage forms and in biological fluids including liquid chromatography tandem mass spectrometry (LCMS-MS), capillary electrophoresis (CE), UV spectrophotometry, LC and high performance thin layer chromatography

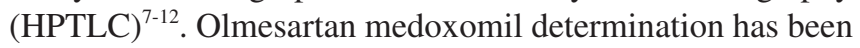
reported for single preparations or in combination with other antihypertensive drugs ${ }^{13-18}$. To best of our knowledge, there is no report of estimation of olmesartan and its prodrug olmesartan medoxomil simultaneously. The aim of this study is to develop a fast, accurate and precise HPLC method for simultaneous determination of olmesartan and olmesartan medoxomil in rabbit plasma. 

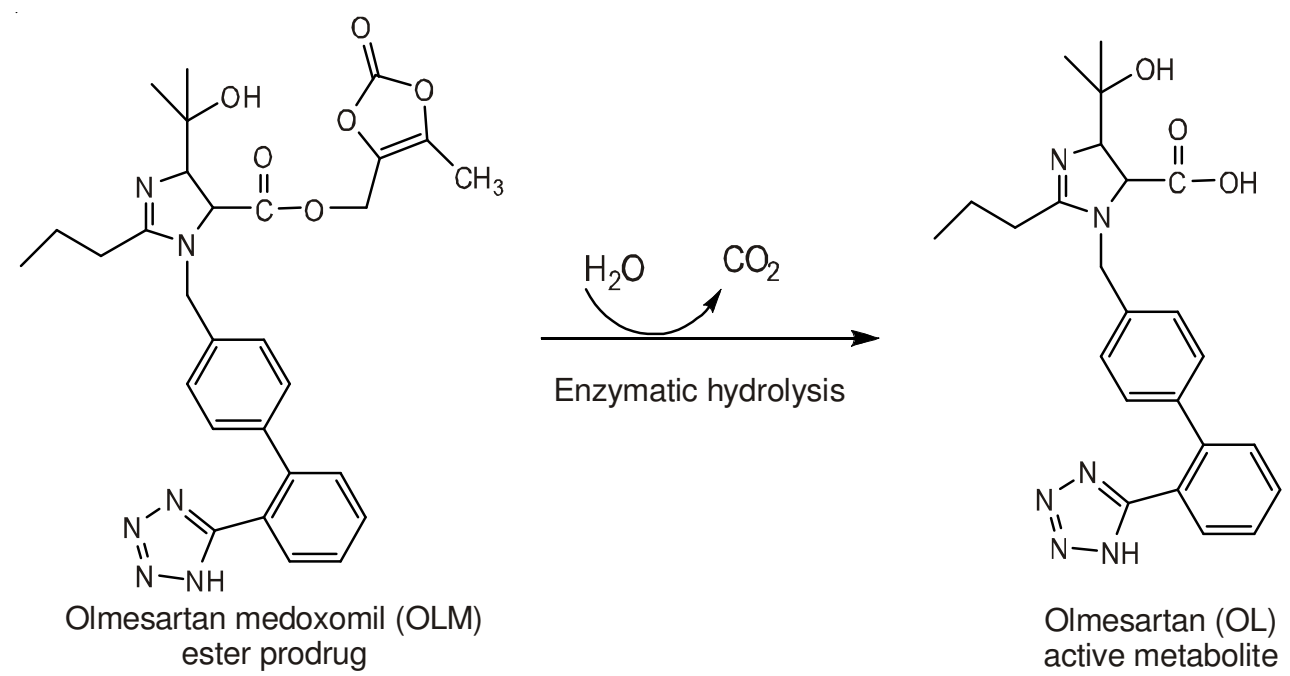

Fig. 1. Hydrolysis of olmesartan medoxomil to olmesartan

\section{EXPERIMENTAL}

Olmesartan medoxomil were provided from Divine SBR International Pvt. Ltd. Irbesartan were supplied by Dr. Reddy's Laboratories Ltd, Hyderabad, India. HPLC grade acetonitrile, methanol, orthophosphoric acid and potassium dihydrogen phosphate and water were obtained from Merck Ltd., Mumbai, India. All solvents and reagents were of analytical or HPLC grade.

Olmesartan medoxomil is a prodrug and active drug olmesartan is available in systemic circulation after hydrolysis in intestinal wall by esterase enzyme. Therefore its hydrolysis was carried out in laboratory to obtain the active parent drug olmesartan. $1 \mathrm{~g}$ ( 1.79 mmoles) of olmesartan medoxomil was dissolved in $10 \mathrm{~mL} 10 \%$ aqueous $\mathrm{NaOH}$, refluxed for $20 \mathrm{~min}$. The alkaline residue in the flask was cooled acidified until definitely acidic. The reaction was monitored by thin layer chromatography (TLC). The mobile phase for TLC was composed of acetonitrile:ethyl acetate:glacial acetic acid (70:30:0.4 $\mathrm{v}: \mathrm{v})$. The $\mathrm{R}_{\mathrm{f}}$ value for olmesartan medoxomil was found to be 0.86 and 0.37 for olmesartan. The reaction mixture was poured in crushed ice; solid olmesartan was separated, filtered off and recrystallized from acetone and its structure was confirmed by IR, MS and ${ }^{1} \mathrm{H}$ NMR.

Instrument and software: Chromatography was performed with Jasco, Japan equipment comprising a PU-2089 plus quaternary pump, degasser and a photo diode array detector (Jasco MD-2010 Plus). The detector was set at $254 \mathrm{~nm}$ and peak areas were integrated automatically by computer using chrompass software program. The plasma samples were processed by using of Micropipettes (Borosil, India), Spinix Vortexer (M37610- 33, Barnstead international, USA), REMI Cooling Centrifuge (Mumbai, India), Ultra-Sonicator (Loba Chem, Mumbai), Nitrogen gas evaporator and Multi-Pulse Vortexer (Glass- COL, USA). Analytical Balance (Sartorius) and pH meter (Lab India) were used.

Experimental animal: Albino rabbits weighing 1.5-2.5 $\mathrm{kg}$ [housed in a temperature $\left(22 \pm 1{ }^{\circ} \mathrm{C}\right)$ and relative humidity $(55 \pm 10 \%)$ controlled room] were used in the experiments. The rabbits were maintained in accordance with the principles declared by Committee for the Purpose of Control and
Supervision of Experiments on Animals (CPCSEA, Govt of India). The rabbits were orally administered the $20 \mathrm{mg}$ olmesartan medoxomil containing tablets.

Chromatographic conditions: HPLC analysis was performed using Symmetry C18 column $(4.6 \mathrm{~mm} \times 150 \mathrm{~mm}$, $5.0 \mu \mathrm{m})$. The mobile phase consisted of Acetonitrile and $0.1 \%$ aqueous triethylamine adjusted to $\mathrm{pH} 6$ with orthophosphoric $\operatorname{acid}(90: 10 \mathrm{v} / \mathrm{v})$. The eluent was monitored with PDA detector at 254 with a flow rate of $1 \mathrm{~mL} / \mathrm{min}$ and sample size of $20 \mu \mathrm{L}$ was carried out at room temperature all over the study.

Stock solution and standards: Stock solutions of olmesartan and olmesartan medoxomil $1000 \mathrm{ng} \mathrm{mL}^{-1}$ were prepared in methanol separately. An accurately weighed irbesartan was dissolved in $10 \mathrm{~mL}$ methanol to obtain 1000 $\mathrm{ng} \mathrm{mL} \mathrm{m}^{-1}$ of stock solution. The stock solution was diluted with methanol to obtain a solution of $50 \mathrm{ng} \mathrm{mL}^{-1}$.

Calibration curves were constructed in methanol by preparing a series of binary mixture of olmesartan medoxomil and olmesartan. Concentration of olmesartan medoxomil and olmesartan were 2, 5, 10, 20, 50 and $100 \mathrm{ng} \mathrm{mL}^{-1}$ and 0.5, 1, 2, 5,10 and $20 \mathrm{ng} \mathrm{mL}^{-1}$, respectively. A solution of IS (50 ng $\mathrm{mL}^{-1}$ ) was also prepared in methanol.

Calibration curves were also constructed in rabbit plasma. These involved replicate analysis of plasma samples spiked with varying concentrations of olmesartan medoxomil and olmesartan were 2, 5, 10, 20, 50 and $100 \mathrm{ng} \mathrm{mL}^{-1}$ and 0.5, 1, 2, 5,10 and $20 \mathrm{ng} \mathrm{mL}^{-1}$, respectively. A solution of IS (50 ng $\mathrm{mL}^{-1}$ ) was also prepared in methanol.

Extraction efficiency: The recovery of an analyte is the extraction efficiency of an analytical process, reported as a percentage of known amount of an analyte carried through the sample extraction and processing steps of the method. Different organic extraction solvents (i.e., methanol, methyl acetate, ethyl acetate, diethyl ether, $n$-hexane, chloroform and acetonitrile) were tried in the experiments and acetonitrile was proved to be most efficient in extracting olmesartan from rabbit plasma and had a small variation in extraction recoveries over the concentration range. Spiked plasma samples were prepared in triplicate at single concentration of $20 \mathrm{ng} \mathrm{mL}^{-1}$ of olmesartan medoxomil and $5 \mathrm{ng} \mathrm{mL}^{-1}$ of olmesartan and assayed as described above. The extraction efficiency of olmesartan medoxomil and 
olmesartan was determined by comparing the peak areas measured after analysis of spiked plasma with those found after direct injection of non biological (un-extracted) samples into chromatographic system at the same concentration levels.

Preparation of plasma samples: An aliquot quantity of $100 \mu \mathrm{L}$ of rabbit plasma spiked with $10 \mu \mathrm{L}$ of calibration standard drugs (olmesartan medoxomil and olmesartan) were taken in a $2 \mathrm{~mL}$ stopper centrifuge tube and mixed for $20 \mathrm{~s}$. The drug was extracted by vortexing with $1.5 \mathrm{~mL}$ of acetonitrile in a spinix vortexer for $10 \mathrm{~min}$ followed by centrifugation at 10,000 rpm for 5 min at $4{ }^{\circ} \mathrm{C}$. The organic phase was withdrawn and dried using nitrogen evaporator. The residue was constituted with $100 \mu \mathrm{L}$ of mobile phase and $20 \mu \mathrm{L}$ was injected into the column.

Validation of method: Plasma samples were quantified using the peak area ratio of olmesartan medoxomil or olmesartan to irbesartan. To evaluate linearity, calibration standards in plasma at concentrations of olmesartan medoxomil and olmesartan were $2,5,10,20,50$ and $100 \mathrm{ng} \mathrm{mL}^{-1}$ and $0.5,1,2,5,10$ and $20 \mathrm{ng} \mathrm{mL}^{-1}$, respectively were prepared and assayed in triplicate on three consecutive days. The accuracy and precision were assayed by determining quality control (QC) samples at three different days. The accuracy (R.E) was expressed as (mean observed concentration-spiked concentration)/(spiked concentration) $\times 100 \%$ and the precision as relative standard deviation (R.S.D). Concentrations of olmesartan medoxomil and olmesartan in plasma samples were determined by backcalculation of the observed peak area ratios of analytes to internal standard from the best-fit calibration curve using a weighted $(1 / x 2)$ linear regression. In order to calculate the extraction recoveries of olmesartan medoxomil and olmesartan at three QC levels (2, 20 and $\left.100 \mathrm{ng} \mathrm{mL}^{-1}\right)$ and $\left(0.5,5\right.$ and $\left.20 \mathrm{ng} \mathrm{mL}^{-1}\right)$, respectively, $\mathrm{n}=3$ at each concentration and internal standard $(n=3)$, the peak area of the plasma extracts were compared to the peak areas of olmesartan medoxomil and internal standard and olmesartan and internal standard that were added to the extracted blank samples at the same concentration ${ }^{19-23}$.

\section{Stability studies}

Pharmacokinetic studies in rabbits: The method described above was applied to quantify the plasma concentration of olmesartan in a single-dose pharmacokinetic study conducted on three white male albino rabbits. The protocol was approved by the institutional Ethical Committee at the School of Pharmaceutical Sciences, Bhubaneswar, Odisha, India. The experiments were conducted as per CPCSEA guidelines. The rabbits weighing 1.5-2.5 kg were housed with free access to food and water, except for $12 \mathrm{~h}$ before experimentation. After single oral administration of $20 \mathrm{mg}$ of olmesartan medoxomil, $2.5 \mathrm{~mL}$ of blood samples were collected from marginal ears vein at 0 ,
$0.5,1,2,3,4,6,9,12$ and 24 time points into heparinised collection tubes. The blood was immediately centrifuged (1000 $\times \mathrm{g}$ ) for $10 \mathrm{~min}$ at $4{ }^{\circ} \mathrm{C}$. The supernatant plasma layer was separated and stored at $-20^{\circ} \mathrm{C}$ until analyzed. The plasma sample were analyzed for olmesartan concentrations as described above. The total area under the observed plasma concentrationtime curve (AUC) was calculated using linear trapezoidal rule. The first order elimination rate constant $\left(\mathrm{K}_{\mathrm{e}}\right)$ was estimated by least square regression of the points describing the terminal $\log$-linear decaying rate phase. $\mathrm{t}_{1 / 2}$ was derived from $\mathrm{K}_{\mathrm{e}}\left(\mathrm{t}_{1 / 2}=\right.$ In $2 / K_{e}$ ). The maximum observed olmesartan concentration $\left(\mathrm{C}_{\max }\right)$ and the time at which $\left(\mathrm{C}_{\max }\right)$ was observed $\left(\mathrm{t}_{\max }\right)$ were reported directly from the profile.

\section{RESULTS AND DISCUSSION}

In order to achieve simultaneous elution of the two components, we used different chromatographic conditions. Various stationary phases like Cyano, C8 and C18 were used (Table-1). The resolution between olmesartan medoxomil and olmesartan was not satisfactory with Cyano and C8. The best results were obtained by using C-18 column. Various mobile phase such as (a) Methanol: water (90:10, 80:20, 75:25 (v/v)), (b) Methanol: $0.1 \%$ aqueous triethylamine adjusted to $\mathrm{pH} 6$ with orthophosphoric acid (90:10, 75:25, 50:50(v/v)), (c) Acetonitrile: 0.01 M phosphate buffer pH 6 [90:10, 50:50 (v/v)] and (d) acetonitrile: $0.1 \%$ aqueous triethylamine adjusted to $\mathrm{pH} 6$ with orthophosphoric acid (90:10 v/v) were tested. With solvent system (a) and (b) the separation between olmesartan medoxomil and olmesartan was not satisfactory. The peak tailing for both the component was more than 2 with solvent system (c). To minimise the peak tailing, we used acetonitrile and $0.1 \%$ aqueous triethylamine adjusted to $\mathrm{pH} 6$ with orthophosphoric acid $(90: 10 \mathrm{v} / \mathrm{v})$. Peak tailing for both the components were found to be well within the limits of 2 .

Under these optimized conditions, the analyte peaks were well resolved and were free from tailing. The tailing factor was $<2$ for both the peaks. The elution order was olmesartan medoxomil $\left(\mathrm{t}_{\mathrm{r}}=3.23 \mathrm{~min}\right)$ and olmesartan $\left(\mathrm{t}_{\mathrm{r}}=4.85 \mathrm{~min}\right)$, at a flow rate of $1 \mathrm{~mL} / \mathrm{min}$. The overlaid PDA spectrum of olmesartan medoxomil and olmesartan showed maximum response at wavelength of $254 \mathrm{~nm}$. Fig. 2 shows a typical chromatogram of olmesartan medoxomil and olmesartan.

Selectivity: The method selectivity was assessed by comparing the chromatograms of blank rabbit plasma with the corresponding spiked plasma. Fig. 2 showed the typical chromatograms of blank plasma sample, plasma sample spiked with olmesartan medoxomil, olmesartan and IS and Clinical plasma sample taken from a rabbit $1 \mathrm{~h}$ after a $20 \mathrm{mg}$ oral dose of olmesartan medoxomil. No significant interferences of

\begin{tabular}{lcc} 
& \multicolumn{2}{c}{ TABLE-1 } \\
& \multicolumn{1}{c}{ STATIONARY PHASES USED TO OPTIMIZE THE METHOD } \\
\hline Stationary phase & Dimension & Observation \\
\hline HiQ sil CN & $4.6 \mathrm{~mm} \times 250 \mathrm{~mm}, 5.0 \mu \mathrm{m}$ & Broad peaks, poor resolution \\
HiQ sil C8 & $4.6 \mathrm{~mm} \times 250 \mathrm{~mm}, 5.0 \mu \mathrm{m}$ & Blunt peak shape, poor resolution \\
HiQ sil C18 & $4.6 \mathrm{~mm} \times 250 \mathrm{~mm}, 5.0 \mu \mathrm{m}$ & Symmetric peaks and satisfactory resolutions \\
Kromasil 100-C-18 & $4.6 \mathrm{~mm} \times 250 \mathrm{~mm}, 5.0 \mu \mathrm{m}$ & Symmetric peaks and satisfactory resolutions \\
Symmetry C18 & $4.6 \mathrm{~mm} \times 150 \mathrm{~mm}, 5.0 \mu \mathrm{m}$ & Symmetric peaks and good resolutions \\
\hline
\end{tabular}



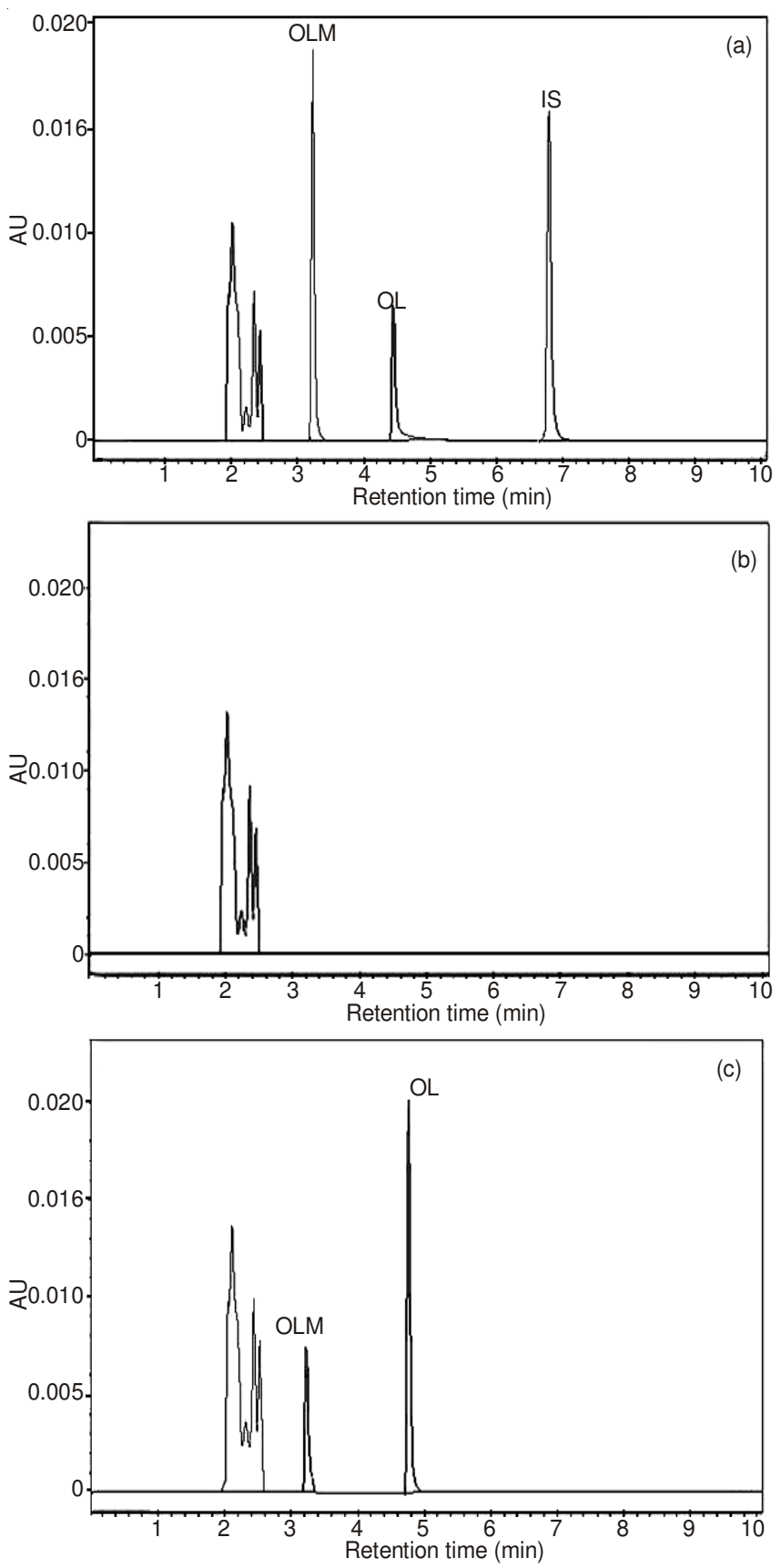

Fig. 2. Representative chromatogram for determination of olmesartan medoxomil and olmesartan in rabbit plasma samples; (a) Representative chromatogram of plasma sample spiked with olmesartan medoxomil , olmesartan and IS, (b) Representative chromatogram of blank plasma of rabbit; (c) Clinical plasma sample taken from a rabbit $1 \mathrm{~h}$ after a $20 \mathrm{mg}$ oral dose of olmesartan medoxomil

endogenous substances from the blank rabbit plasma with olmesartan medoxomil, olmesartan, or IS were detected. Therefore, the described LC method was selective for the determination of olmesartan medoxomil and olmesartan in rabbit plasma.

Linearity, precision and accuracy: Calibration standards were prepared in blank rabbit plasma to give plasma concentration 2, 5, 10, 20, 50, $100 \mathrm{ng} \mathrm{mL}^{-1}$ for olmesartan medoxomil

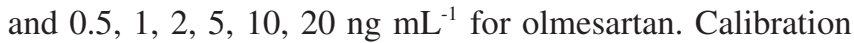
plots were linear over the range 2-100 $\mathrm{ng} \mathrm{mL}^{-1}$ for olmesartan medoxomil and $0.5-20 \mathrm{ng} \mathrm{mL}^{-1}$ for olmesartan, with satisfactory correlation co-efficient $(>0.996)$. Precision and accuracy were determined by analyzing spiked plasma samples at three concentrations for olmesartan medoxomil (2, 20 and $\left.100 \mathrm{ng} \mathrm{mL}^{-1}\right)$ and olmesartan $\left(0.5,5\right.$ and $\left.20 \mathrm{ng} \mathrm{mL}^{-1}\right)$ with respect to the expected concentrations in a calibration graph and the results are shown in Table-3. Intra-day accuracy and precision ranged from -0.22 to 6.3 and 0.54 to $10.34 \%$ for olmesartan medoxomil ; -1.88 to -0.35 and 0.86 to $7.52 \%$ for olmesartan respectively. Inter-day accuracy and precision ranged from -0.17 to 2.5 and 0.27 to $6.97 \%$ for olmesartan medoxomil; -0.44 to 2 and 0.02 to $2.83 \%$ for olmesartan respectively. The results indicate that the method is precise and accurate.

Extraction recovery: The recoveries were determined by comparing peak areas of extracted standards with those of un-extracted standards across the range of standard curve. The mean recoveries of the analytes were $97 \%$ for olmesartan medoxomil and $84 \%$ for olmesartan over the constructed calibration concentration ranges.

Limits of detection (LOD) and limit of quantification (LOQ): The LOD was found to be $0.63 \mathrm{ng} / \mathrm{mL}$ and LOQ was found to be $1.92 \mathrm{ng} / \mathrm{mL}$ for olmesartan medoxomil and the LOD was found to be $0.54 \mathrm{ng} / \mathrm{mL}$ and the LOQ was found to be $1.66 \mathrm{ng} / \mathrm{mL}$ for olmesartan, respectively.

Pharmacokinetic studies in rabbits: The developed method was applied to quantify olmesartan concentration in pharmacokinetic study carried out on rabbits. The mean plasma concentration versus time profile following a single oral administration of olmesartan medoxomil to three rabbits is presented in Fig. 3. The pharmacokinetic parameters are summarized in Table-2.

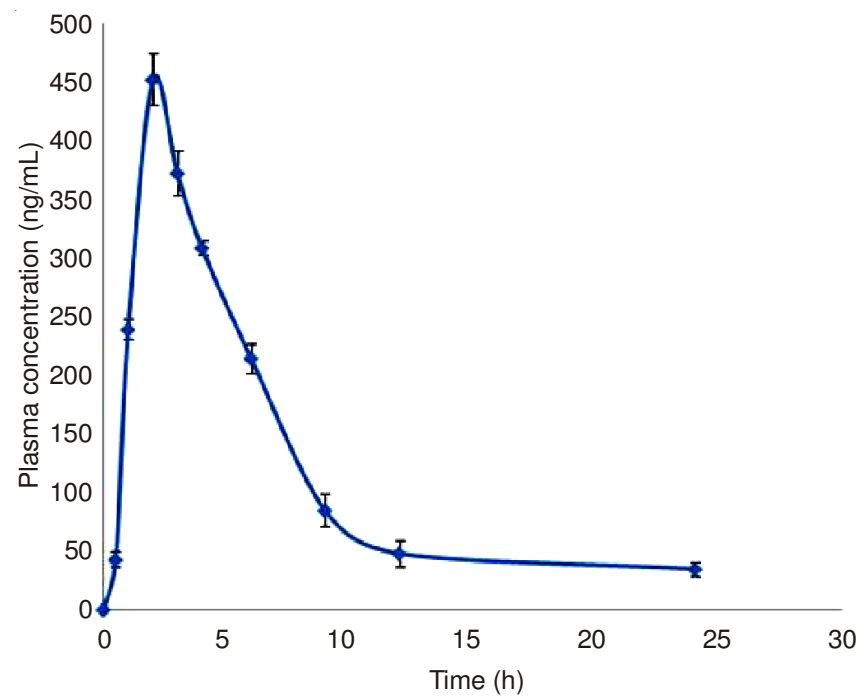

Fig. 3. Mean plasma drug concentration vs. time profile after single oral administration of olmesartan medoxomil $(20 \mathrm{mg})$ in rabbits

\section{Conclusion}

A novel simple and sensitive reversed-phase HPLC isocratic method has been developed and validated for the estimation of olmesartan and its prodrug olmesartan medoxomil in rabbit plasma using PDA detector. A good resolution was obtained between olmesartan medoxomil, olmesartan and IS with retention time $3.234 .85 \mathrm{~min}$ and $6.90 \mathrm{~min}$, respectively. There were no peak interference observed around the retention time 


\begin{tabular}{|c|c|c|c|c|}
\hline & \multicolumn{4}{|c|}{$\begin{array}{l}\text { PRECISION AND ACCURACY OF THE MET } \\
\text { OLMESARTAN MEDOXOMIL AND }\end{array}$} \\
\hline \multirow{2}{*}{ Compound } & \multirow{2}{*}{$\begin{array}{c}\text { Conc. } \\
\text { (ng/mL) }\end{array}$} & \multicolumn{3}{|c|}{ Intra-day precisior } \\
\hline & & \multicolumn{2}{|c|}{ Mean \pm SD $(\mathrm{ng} / \mathrm{mL})$} & R.S.D. \\
\hline \multirow{3}{*}{$\begin{array}{l}\text { Olmesartan } \\
\text { medoxomil }\end{array}$} & 2 & \multicolumn{2}{|c|}{$2.13 \pm 0.22$} & 10. \\
\hline & 20 & \multicolumn{2}{|c|}{$19.8 \pm 0.20$} & 1.0 \\
\hline & 100 & \multicolumn{2}{|c|}{$99.78 \pm 0.58$} & 0.5 \\
\hline \multirow{3}{*}{ Olmesartan } & 0.5 & \multicolumn{2}{|c|}{$0.49 \pm 0.04$} & 7.52 \\
\hline & 5 & \multicolumn{2}{|c|}{$4.91 \pm 0.21$} & 4.21 \\
\hline & 20 & \multicolumn{2}{|c|}{$19.93 \pm 0.17$} & \\
\hline \multicolumn{5}{|c|}{$\begin{array}{l}\text { S.D., standard deviation; R.S.D., relative standard deviation; R.E., relat } \\
\text { /nominal concentration) }\end{array}$} \\
\hline \multicolumn{5}{|c|}{$\begin{array}{c}\text { TABLE-2 } \\
\text { PHARMACOKINETIC PARAMETERS OF SINGLE DOSE } \\
\text { ADMINISTRATION OF } 20 \text { mg OLMESATRAN } \\
\text { MEDOXOMIL TO RABBITS }(\mathrm{n}=3)\end{array}$} \\
\hline \multicolumn{3}{|c|}{ Pharmacokinetic parameters } & \multicolumn{2}{|c|}{ Observed Values } \\
\hline \multirow{2}{*}{\multicolumn{3}{|c|}{$\begin{array}{l}\text { Maximum plasma concentration }(\mu \mathrm{g} / \mathrm{mL}) \mathrm{C}_{\max } \\
\text { Time required to reach maximum plasma } \\
\text { concentration } \mathrm{t}_{\max }(\mathrm{h})\end{array}$}} & \multicolumn{2}{|c|}{$467 \mathrm{ng} / \mathrm{mL}$} \\
\hline & & & & \\
\hline \multicolumn{3}{|c|}{ Area under the curve, $\mathrm{AUC}_{0 \mathrm{t}}(\mathrm{h} \mu \mathrm{g} / \mathrm{mL})$} & \multicolumn{2}{|c|}{3717.27 (h ng/mL) } \\
\hline \multicolumn{3}{|c|}{ Area under the curve, $\mathrm{AUC}_{0-\infty}\left(\mathrm{h}^{2} \mu \mathrm{g} / \mathrm{mL}\right)$} & \multicolumn{2}{|c|}{$3810.20(\mathrm{~h} \mathrm{ng} / \mathrm{mL})$} \\
\hline \multicolumn{3}{|c|}{ Elimination half life, $t_{1 / 2}(h)$} & \multicolumn{2}{|c|}{19.8} \\
\hline \multicolumn{3}{|c|}{ Elimination Rate constant $\mathrm{K}_{\mathrm{e}}\left(\mathrm{h}^{-1}\right)$} & \multicolumn{2}{|c|}{0.035} \\
\hline \multicolumn{3}{|c|}{ Mean residence time, MRT(h) } & \multicolumn{2}{|c|}{1.025} \\
\hline \multicolumn{3}{|c|}{ Clearance, $\mathrm{Cl}(\mathrm{L} / \mathrm{h})$} & \multicolumn{2}{|c|}{$1.3 \mathrm{~L} / \mathrm{h}$} \\
\hline
\end{tabular}

of olmesartan medoxomil, olmesartan and IS. Calibration plots were linear over the range 2-100 $\mathrm{ng} \mathrm{mL}^{-1}$ for olmesartan medoxomil and $0.5-20 \mathrm{ng} \mathrm{mL}^{-1}$ for olmesartan with satisfactory co-relation coefficients of ( $>0.996)$. A maximum recovery of the drug from plasma resulted using acetonitrile as extracting solvent. The results obtained proved that the method is rapid, sensitive and reproducible. The method has been successfully applied to pharmacokinetic studies of olmesartan and olmesartan medoxomil in rabbits. The results have demonstrated that olmesartan medoxomil is a prodrug of olmesartan.

\section{ACKNOWLEDGEMENTS}

The authors are thankful to Siksha 'O' Anusandhan University for providing the research facility to carry out the work.

\section{REFERENCES}

1. S.-F. Ma, M. Anraku, Y. Iwao, K. Yamasaki, U. Kragh-Hansen, N. Yamaotsu, S. Hirono, T. Ikeda and M. Otagiri, Drug Metab. Dispos., 33, 1911 (2005).

2. H. Koike, T. Sada and M. Mizuno, J. Hypertens. Suppl., 19, S3 (2001).

3. J. Neutel, Am. J. Cardiol., 87, 37C (2001).

4. J. Brousil and J. Burke, Clin. Ther., 25, 1041 (2003).
5. P. Laeis, K. Puchler and W. Kirch, J. Hypertens., 19, S21 (2001).

6. T. Ikeda, In Proceedings of the International Symposium on Serum Albumin \& á 1 -Acid Glycoprotein: Two Prodrugs Activated by Serum Esterases including Albumin, pp. 173-180 (2000).

7. V.V. Vaidya, S.M.N. Roy, S.M. Yetal, S.S. Joshi and S.A. Parekh, Chromatographia, 67, 147 (2008).

8. T. Murakami, H. Konno, N. Fukutsu, M. Onodera, T. Kawasaki and F. Kusu, J. Pharm. Biomed. Anal., 47, 553 (2008).

9. V.P. Rane, K.R. Patil, J.N. Sangshetti, R.D. Yeole and D.B. Shinde, Chromatographia, 69, 169 (2009).

10. L. Bajerski, C. Paim, A. Pereira, C. Dias, R. Rossi, V. Todeschini, M. Steppe, A. Bergold and P. Fröehlich, Quim. Nova, 36, 34 (2013).

11. D. Liu, P. Hu, N. Matsushima, X. Li, L. Li and J. Jiang, J. Chromatogr. B, 856, 190 (2007).

12. T. Sharma, S.C. Si and D.G. Sankar, J. Pharmacy Res., 3, 1553 (2010).

13. T. Sharma, N. Mishra, S.C. Si and D.G. Sankar, Der Pharm. Lett., 2, 302 (2010)

14. N. Shah, B. Suhagia, R. Shah and N. Patel, Indian J. Pharm. Sci., 69, 834 (2007).

15. M. Celebier and S. Altinoz, Hacettepe Univ. J. Faculty of Pharmacy, 27, 119 (2007).

16. C.V. Patel, A.P. Khandhar, A.D. Captain and K.T. Patel, Eurasian J. Anal. Chem., 2, 159 (2007).

17. P.D. Bari and A.R. Rote, Chromatographia, 69, 1469 (2009).

18. O. Sagirli, A. Önal, S.E. Toker and D. Sensoy, Chromatographia, 66, 213 (2007).

19. ICH, Validation of Analytical Procedures: Text and Methodology Q1A(R2); International Conference on Harmonisation (ICH) of Technical Requirements for Registration of Pharmaceuticals for Human Use, Geneva (2005).

20. ICH, Validation of Analytical Procedures: Text and Methodology Q2B; International Conference on Harmonisation (ICH) of Technical Requirements for Registration of Pharmaceuticals for Human Use, Geneva (2005).

21. British Pharmacopoeia, Her Majesty Stationary Office, London, 2144 (II), (2001).

22. USP, The United States Pharmacopoeia, United States Pharmacopoeia Convention: Rockville, edn 35 (2012).

23. FDA/CDER, Guidance for the Industry: Bioanalytical Method Validation, Department of Health and Human Services, US Food and Drug Administration, Centre for Drug Evaluation and Research (CDER) website. Available: /http://www.fda.gov/cder/guidance/4252fnl.pdf (2001). 